\title{
STEALING AS A FORM OF LIFE
}

So much has been written about the exchange $\mathcal{O}_{\text {between art and anthropology. Alyssa }}$ Grossman's essay runs swiftly and cogently through this literature, focusing on her specific relation to Sophie Calle, which she defines in her title as 'stealing'. That is a contentious term. Some authors speak of mutual inspiration, interpretation, hermeneutics, cooperation, borrowing; at most they qualify this relation in terms of mutual gift-giving (as I have myself). But 'stealing'? Well. That apparently goes too far. Or maybe not. One of the things I think I have learned about the gift is that sometimes it is not far from theft; taking things so as to give them away was the key to the future affluent society for situationists like Raoul Vaneigem, inspired by their readings on the gift in Mauss and Bataille. And yet Grossman does not really explain why she thinks she is 'stealing' from Calle. She mentions 'being relevant' and 'using similar tactics' but nothing that seems to go so far and so deep as stealing. Saying this, my intention is not exactly to question the title of Grossman's essay but perhaps, on the contrary, to delve further into where this idea of 'stealing' takes us: if and how it is substantially different from a quaint 'borrowing'.

Starting with Sophie Calle. As Grossman says, Calle has often been referenced in the literature on art and anthropology but it is not self-evident why she is a good example. Her work is not really interested in cultural difference; she does not do 'fieldwork' that resembles ethnographic fieldwork; she does not address pressing social or political issues (like real-estate speculation, immigration, etc.). One could say that her work deals with gender issues but that would still be a very superficial commentary on Calle; she is not well known just because she deals with gender. She is a woman, and that is relevant for her work. But it would be perfunctory to say that her work is anthropological because of identity politics, even if that is often what 'anthropological' seems to mean for art critics like Hal Foster (1996). Calle does not pretend at all to be an anthropologist, but her work is interesting to anthropologists because of the conceptual questions it raises: because of its intricate experiments with human relations and exchanges.

What appears more contentious in Calle's work are 'methods' like her obsessive stalking which are blatantly inappropriate- 'unethical'for an anthropologist, yet are interesting precisely because of that. The allure of art practice for anthropologists is often based precisely on the fact that artists seem to be allowed to transgress borders in ways that anthropologists cannot even contemplate. In this sense, Grossman is not 'stealing' Calle's more radical practices, but, rather, taking conceptual inspiration from what could be seen as closer to civilised ethnographic fieldwork: conducting interviews, organising workshops, and so on. Yet the more appealing aspects of Calle's work are not those more closely resembling anthropology, but those farther from it. When she follows people or embodies a character, she creates surreal and obsessive situations that bypass the distinction between reality and fiction, performing, rather than representing a given world. Her 'research' character is closer to a detective, as Grossman observes, than to a rule-abiding scientist.

The detective is classically an ambiguous figure, poised between literature and reality, often an amateur (Dupin, Holmes), an eccentric, 
a loner. Under the pretended rationality of detective work, in these characters we can catch a glimpse of the lunatic and the visionary. Their pursuit of the truth does not always coincide with law abidance: they steal evidence from the police, get into fights, conduct break-ins... These ambiguous characters are often involuntarily comical due to the contradictions inherent in the dichotomy of genius and idiot. Performing the role of the detective, Calle underscores the obsessive, compulsive nature of detective research, the absurd and idiotic aspects of this total search for truth and its anti-social methods. In this search, the eccentric detective can bypass or break all social rules-like Calle's calling all the numbers in an address book she found in the street. In L'idiotie (2003), art critic Jean-Yves Jouannais described 'idiotic' art practices that mimic technical lexicons, analytical procedures, and auditing practices, sometimes with maniacal precision, and yet with obvious incompetence; they replace lyricism with inventories, instructions, protocols, and diagrams, creating an economy of signs that is at once Stakhanovite, pseudo-scientific, obsessive, arbitrary, non-motivated, and stupid. The objective of idiotic art seems to be showing the limits of the methodologies it mimics by reducing them to their basics, or better, to the absurd: by questioning their efficiency, effects, results, and procedure. In so doing, they end up, perhaps unwittingly, transgressing the rules of engagement, becoming 'unethical', stealing.

Ultimately, the question seems to be: do we have to take these performances 'seriously'? In Grossman's words, 'So... if social scientists were seriously to engage with Calle's anthropologicalartistic practice- not simply borrow from itwhat might this involve, and what might be revealed?'. Well, perhaps the problem lies in the word 'seriously'. Are Calle's performance's 'serious'? They are indeed seriously undertaken, intensive, obsessive, but, on the other hand, they are also obviously absurd, unprofessional, amateurish, 'unethical'. This contradiction in her idiotic methodologies points, in particular, to the vulnerability of the artist herself: for example, when passing as a hotel maid in order to scrutinise people's possessions. There is inevitably a component of comedy in this vulnerability, but it is precisely in this comedy that the more complex and subtle concepts of her work are found.

Now, can anthropologists 'seriously' follow' her example? In theory, the serious answer would be, no. We are not free to act unethically because we are representatives of a corporation, academia, that is defined by a set of rules. In other words, we are not detectives, we are the police. Yet, in practice, we behave like idiots all the time while doing fieldwork; we are constantly out of place, transgressing rules, if perhaps unwillingly and involuntarily. The big difference between artistic practice and anthropological practice is that artists can focus on the performative aspects of their own vulnerability, while anthropologists have to refrain from it, at least in principle, because of 'professionalism'. Some of us have a guilty admiration for art characters like Calle, who explicitly embrace an aspect of our own practice we feel we have to hide. Arguably, some have tried to open the can of this 'professionalism': for example, in response to Nikolai SsorinChaikov's call for 'ethnographic conceptualism' (2013). But in general terms, I am afraid that we have not progressed far from Foster's ironic assessment of the 'anthropologist as artist' (1996). 


\section{REFERENCES}

Foster, Hal 1996. The Artist as Ethnographer? In Hal Foster (ed.). The Return of the Real: The Avantgarde at the end of the Century. Cambridge: MIT Press.

Jouannais, Jean-Yves 2003. L'idiotie: art, vie, politique-méthode. Paris: Beaux arts magazine.
Ssorin-Chaikov, Nikolai 2013. Ethnographic Conceptualism: An Introduction. Laboratorium 5: 5-18.

\section{ROGER SANSI}

PROFESSOR

UNIVERSITAT DE BARCELONA

rogersansi@ub.edu 